\title{
A "CURA" DO CÂNCER NA TV: A POLÊMICA DA FOSFOETANOLAMINA SINTÉTICA EM PROGRAMAS TELEVISIVOS BRASILEIROS
}

\author{
Dra. (C) Aline Bastos \\ Universidade Federal de Minas Gerais, Belo Horizonte-MG, Brasil \\ aline.bastos@gmail.com \\ ORCID iD: https://orcid.org/0000-0002-5907-6056 \\ Mg. (C) Ana Carolina Pontalti Monari \\ Universidade Estadual Paulista "Júlio de Mesquita Filho", Bauru-SP, Brasil \\ capmonari@gmail.com
}

Recibido el 29 de octubre de 2018

Aceptado el 29 de noviembre de 2018

\section{Resumo}

Este artigo tem como objetivo investigar como os programas televisivos Fantástico e Domingo Espetacular, respectivamente das Redes Globo e Record, apresentaram uma nova descoberta científica - a fosfoetanolamina sintética - para a sociedade brasileira. A disputa simbólica e discursiva ao redor da pílula ficou evidente na polifonia demonstrada. Duas versões da mesma história foram apresentadas para o público, praticamente no mesmo horário, em duas emissoras de televisão diferentes. Enquanto o programa Fantástico enfocou os perigos de se utilizar um composto químico sem comprovação terapêutica; o programa Domingo Espetacular direcionou a sua abordagem para os relatos dos pacientes e para as possíveis melhorias atribuídas à "pílula do câncer". Para o estudo, foram utilizadas a análise hermenêutica, sob a luz das teorias de comunicação de ciência e midiatização.

Palavras chave: Comunicação de Ciência, Midiatização, Fosfoetanolamina sintética, Fantástico, Domingo Espetacular. 


\title{
CANCER "CURE" ON TV: THE SYNTHETIC PHOSPHOETHANOLAMINE CONTROVERSY IN BRAZILIAN TELEVISION PROGRAMS
}

\begin{abstract}
This article aims to investigate how Fantástico and Domingo Espetacular television programs, from TV Globo and TV Record respectively, presented a new scientific discovery - synthetic phosphoethanolamine - to Brazilian society. The simbolic and discursive dispute around the pill was evident in the polyphony presented. Two versions of the same history were presented to the public, virtually at the same time, on two different channels. While Fantástico focused on the hazards of using the chemical compound without therapeutic evidence; Domingo Espetacular focused its approach on patient reports and the possible improvements in health attributed to the "cancer pill". For this study, we have used hermeneutic analysis, as well as science communication and midiatization theories.
\end{abstract}

Keywords: Science Communication, Midiatization, Synthetic Phosphoethanolamine, Fantástico, Domingo Espetacular. 


\section{LA "CURACIÓN" DEL CÁNCER EN LA TELEVISIÓN: LA POLÉMICA DE LA FOSFOETANOLAMINA SINTÉTICA EN PROGRAMAS TELEVISIVOS BRASILEÑOS}

\section{Resumen}

Este artículo tiene como objetivo analizar cómo los programas televisivos Fantástico y Domingo Espetacular, respectivamente de las Redes Globo y Record, presentaron un nuevo descubrimiento científico - la fosfoetanolamina sintética - a la sociedad brasileña. La disputa simbólica y discursiva alrededor de la píldora quedó evidente en la polifonía demonstrada. Dos versiones de la misma historia fueron presentadas al público, prácticamente al mismo tiempo, en dos emisoras de televisión diferentes. Mientras que el programa Fantástico enfocó los peligros de utilizar un compuesto químico sin comprobación terapéutica; el programa Domingo Espetacular dirigió su enfoque a los relatos de los pacientes y las posibles mejoras atribuidas a la "píldora del cáncer". Para el estudio, se utilizaron el análisis hermenéutico y las teorías de la comunicación de ciencia y mediatización.

Palabras clave: Comunicación de Ciencia, Mediatización, Fosfoetanolamina Sintética, Fantástico, Domingo Espetacular.

\section{Como citar este artículo:}

Bastos, A., Pontalti, A. (2019). "A "Cura" Do Câncer Na Tv: A Polêmica Da Fosfoetanolamina Sintética Em Programas Televisivos Brasileiros", en Perspectivas de la Comunicación, Vol. 12, N² 1. pp. 37-58. 
Introdução

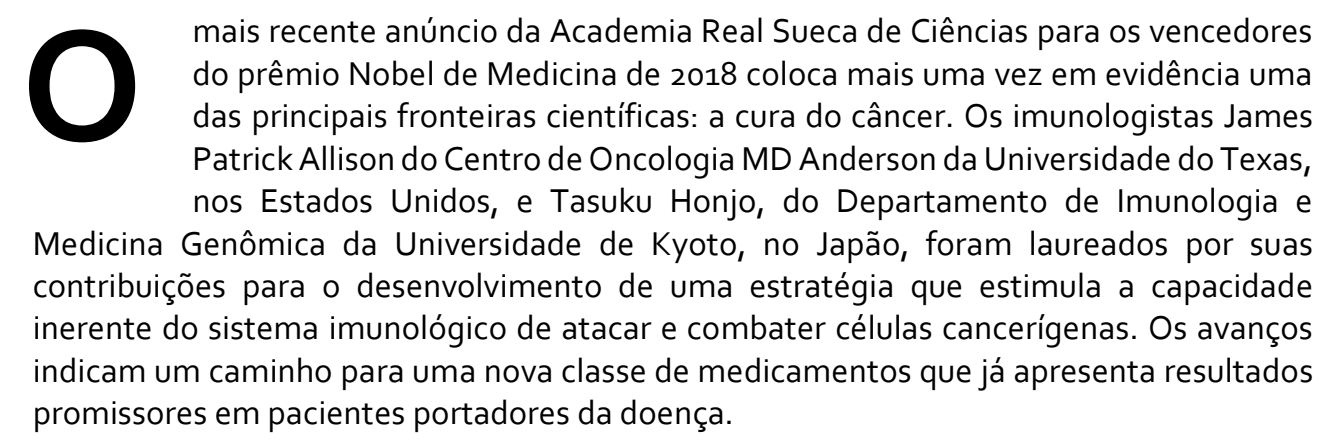

mais recente anúncio da Academia Real Sueca de Ciências para os vencedores do prêmio Nobel de Medicina de 2018 coloca mais uma vez em evidência uma das principais fronteiras científicas: a cura do câncer. Os imunologistas James Patrick Allison do Centro de Oncologia MD Anderson da Universidade do Texas, nos Estados Unidos, e Tasuku Honjo, do Departamento de Imunologia e Medicina Genômica da Universidade de Kyoto, no Japão, foram laureados por suas contribuições para o desenvolvimento de uma estratégia que estimula a capacidade promissores em pacientes portadores da doença.

Os estudos de substâncias imunomoduladoras para o tratamento e cura do câncer começou a se estabelecer no meio científico no início da década de 199o. Foi exatamente nessa época que o professor Gilberto Orivaldo Chierice, do Instituto de Química da Universidade de São Paulo (USP), campus São Carlos, iniciou há 20 anos seus estudos com a fosfoetanolamina sintética, presente em todas as células do corpo humano em quantidades distintas. A substância sintetizada em laboratório, conforme procedimento submetido à proteção intelectual (patente), teria uma função a mais em células cancerígenas: sinalizá-las para que o próprio organismo pudesse eliminá-las naturalmente, utilizando as defesas de seu sistema imunológico.

Durante mais de 20 anos, pacientes com câncer compareceram voluntariamente ao laboratório do docente para receber gratuitamente o suposto medicamento e relatavam os benefícios do procedimento, sobretudo, entre seus amigos e familiares e, posteriormente, nas redes sociais. Em 2014, a USP publicou, no entanto, a portaria $n^{\circ} 1.389$ que proibiu a distribuição de medicamentos em suas dependências. A partir desse novo regulamento, os pacientes com câncer começaram a ingressar na Justiça para conseguir, via medida judicial, as "pílulas do câncer".

Meses mais tarde, toda a comoção popular pela liberação da droga motivou parlamentares a elaborarem a lei $13.269 / 16$, que autorizou o acesso à fosfoetanolamina sintética por pacientes oncológicos, sem comprovação científica de sua eficácia e sem registro nos órgãos de vigilância sanitária. Dois meses após a sua promulgação, o Supremo Federal Tribunal suspendeu a lei de forma liminar, motivado por uma Ação Direta de Inconstitucionalidade ajuizada pela Associação Médica Brasileira (AMB).

A primeira reportagem sobre a fosfoetanolamina sintética foi veiculada pelo Portal de Notícias G1 - São Carlos e Araraquara em 17 de agosto de 2015, sendo posteriormente ampliada em reportagem para a EPTV, emissora de televisão afiliada à Rede Globo em São Carlos (SP). Meses depois, o caso começou a ser divulgado nas emissoras de televisão brasileiras com maior nível de audiência: Globo, Record e SBT. No Brasil, com uma população de mais de 200 milhões de pessoas, segundo dados do Instituto Brasileiro de Geografia e Estatística (IBGE), há televisão em 97,2\% das residências - isso representa cerca de mais de 67 milhões de domicílios com telespectadores (IBGE, 2016). 
Diante desse fato, este artigo busca analisar como os programas televisivos Fantástico e Domingo Espetacular, respectivamente das TVs Globo e Record, abordaram a questão da fosfoetanolamina sintética. $O$ caso foi selecionado por causa de suas características próprias, tais como um conteúdo regional que ganhou repercussão nacional, suas controvérsias científicas e regulatórias, o despertar de anseios políticos e econômicos e a comoção da população por uma possivel cura do câncer. Para isso, serão utilizadas os aportes teóricos da midiatização e comunicação de ciência, e a metodologia da análise hermenêutica.

\section{Comunicação de ciência}

A comunicação em ciência desenvolveu-se principalmente em relação a dois processos gerais: a institucionalização do cientista como uma profissão de maior status social e crescente especialização; e o avanço das ferramentas de comunicação (Bucchi, 2008). A comunicação de ciência é normalmente dividida em dois níveis: primário (interpares) e secundária (pública/mediada) (Bucchi, 2008; Bueno, 2010; Epstein, 2012). Entende-se por comunicação primária da ciência ou comunicação científica, a troca de informaç,ões entre membros da mesma comunidade científica, através de meios formais como periódicos, anais e congressos ou informais como redes virtuais, "colégio invisível" e contatos pessoais. "Por meio da comunicação científica, os membros dessa comunidade se mantêm informados sobre as tendências da área, os estudos já realizados e seus resultados" (Epstein, 2012:15). O acesso à comunicação científica tem sido bastante favorecido pelas novas tecnologias, que estimulam e potencializam a implantação de ambientes que reúnem número significativo de periódicos e redes de interação entre os cientistas. Já a comunicac,ão secundária é a divulgação científica ou popularização do conhecimento científico, que pode ser realizada tanto pelo divulgador ou jornalista científico, mediador entre o cientista e o público, como pelo próprio cientista, que assume então papel do divulgador para o público leigo (Epstein, 2012:15). "A diferenç,a entre esses dois conceitos é que a divulgação está ligada à popularização da ciência, levando os conhecimentos científicos ao público leigo em geral, enquanto a comunicação científica ocorre entre um grupo seleto formado de especialistas" (Bueno, 2010: 24).

Sabe-se que a mídia tem sido identificada não só como a principal fonte de informações de Ciência e Tecnologia (C\&T), mas também a fonte de informação preferida por parte dos consumidores (Fao/Who, 2004). A mídia desempenha um papel crucial no fornecimento de informações necessárias para tomada de decisões sobre riscos, benefícios e opções de consumo associados aos produtos derivados da Ciência e Tecnologia. Além disso, a mídia tem o potencial de permitir aos cidadãos ter acesso e poder avaliar as informações públicas, além de facilitar o debate e o diálogo entre eles. Assim, a mídia desempenha importante papel no fomento das mobilizações sociais no espaço público em questões de C\&T.

Di Giulio e Figueiredo (2006) citam que a difusão científica colabora para a própria democratização do conhecimento. Oliveira (2012:15) retoma esse pensamento, ao dizer que "o jornalismo científico pode entrar em cena como agente facilitador na construção da cidadania". Para ela, a divulgação científica aproxima o cidadão comum dos benefícios que ele tem o direito de reivindicar para melhoria do bem-estar social, além de oferecer uma visão mais clara e objetiva da realidade, ao contrapor aspectos e crenças que impedem que as pessoas localizem os efeitos dos problemas que enfrentam em seu dia-a-dia. 


\begin{abstract}
"(...) o acesso às informações sobre C \& T é fundamental para o exercício pleno da cidadania e, portanto, para o estabelecimento de uma democracia participativa, na qual grande parte da população tenha condições de influir, com conhecimento, em decisões e ações políticas ligadas à C \& T. Entendemos que a formação de uma cultura científica notadamente em sociedades emergentes como é o caso do Brasil, não é processo simples ou que possa se empreender em pouco tempo. No entanto, o acesso às informações sobre $C \&$ T como um dos mecanismos que pode contribuir de maneira efetiva para a formação de uma cultura científica deve ser facilitado ao grande público carente delas". (Oliveira, 2012: 13).
\end{abstract}

A pesquisadora alerta que a consequência mais "cruel" da falta de educação e de informação é a incapacidade de poder opinar ou decidir sobre coisas que podem afetar a vida individual, comunitária e até mesmo de toda uma nação. Com o acesso à dados e notícias sobre ciência, por exemplo, a população pode interpretar esses conteúdos e tecer suas próprias opiniões sobre os assuntos, o que promove, além da cidadania, o debate público.

A disseminação da informação pela mídia sobre a possível eficácia da fosfoetanolamina sintética no tratamento do câncer despertou a atenção popular. A repercussão midiática a favor da liberação do uso da substância para os pacientes, principalmente nos programas de televisão, pode ter contribuído para a sensibilização de agentes públicos e políticos, que estão abrindo caminhos para questionamentos e influência de não cientistas nos modos de produção da Ciência no Brasil.

\title{
Mídia e Debate Social
}

Nas últimas décadas, os estudos sociais sobre mídia começam a considerar a complexidade de seus efeitos, abandonando a abordagem conhecida como "agulha hipodérmica" ou "bala mágica", de efeitos diretos e imediatos a indivíduos que passivamente recebem o conteúdo midiático. Cada vez mais se reconhece que o poder social da mídia obedece a padrões diferenciados que não pode ser considerado de forma homogênea; já que são distintos os níveis de envolvimento pessoal, comportamento e racionalidades que cada indivíduo é capaz de mobilizar em seu domínio de ação.

Uma perspectiva crítica dos efeitos da mídia estabelece, portanto, uma concepção mais aprofundada da dinâmica comunicacional no espaço público; e, assim, reconceitualiza os conceitos de sua audiência. Os públicos "não se reduzem à forma cristalizada de um espaço público institucional, mas que são também capazes de dinamizar outros espaços públicos autônomos, abertos ao mundo da vida" (Esteves, 2016: 468).

Essa abordagem nos leva pensar a midiatização como uma força de moldagem mais aberta a um envolvimento e à participação do indivíduo em função de produção e reprodução permanente de sentidos, como já foi apontado na década de 1980 por Stuart Hall, em seu artigo Coding/Decoding (Hall, 1980). Partimos, todavia, de uma premissa que estamos, de fato, imersos em uma "cultura da mídia" moldado pelo processo de mediação por recursos tecnológicos de comunicação, chamado de "midiatização" (Hepp, 2013; Hjavard, 2012). "Não se trata mais de encarar a mídia como uma instituição independente que impacta outras instituições. Ao invés disso, é preciso levar em consideração o fato de que vivemos em mundos que estão saturados de meios de comunicação" (Hepp, 2013: 128, tradução nossa). 
Isso quer dizer que a mídia pode determinar ou influenciar uma agenda de assuntos que preenche a atenção dos públicos ao elencar matérias prioritárias que ganham maior visibilidade no espaço público, conforme preconiza a teoria da agenda-setting (McCombs, 1981). A mídia pode até não definir, propriamente, o sentido do mundo, "mas baliza (através da sua agenda) com notável exatidão de limites que esse sentido pode assumir, isto é, os limites do nosso pensamento sobre a realidade envolvente" (Esteves, 2016: 393). Esse poder facilmente se justifica pelo fato de nossa experiência simbólica ser cada vez mais adquirida de uma forma indireta, e não mais através de um contato direto com a realidade, mas de uma forma mediada ou, mais precisamente, midiatizada.

O papel fundamental da mídia parece estar centrado cada vez mais, como já apontou Lippmann (1922) na década de 1920, na organização cognitiva do mundo ao nosso redor. Em larga medida, a mídia é responsável por construir "mapas de mundo", para nos orientar como ter contato direto e pessoal com a realidade exterior. "O ambiente real tornou-se demasiado grande, demasiado complexo, demasiado mutável para que dele possamos ter um conhecimento direto. (...) Para cruzar o mundo, o homem necessita de "mapas do mundo"'" (Lippmann, 1922: 16). Esses mapas de mundo seriam sentidos e imagens estereotipadas potencialmente criadas pela mídia, de modo a tentar direcionar nossos hábitos, gostos, capacidades, esperanças, emoções, opiniões e até comportamentos.

Tradicionalmente, o termo opinião pública relaciona-se à seleção de um conjunto de temas prioritários para debate público, essenciais para o sistema político (Habermas, 2012; Luhmann, 2000). Contemporaneamente, esse conceito vem sendo reformulado, de uma forma distinta de seu sentido original. A opinião pública ressurge agora num contexto de alta tecnologização da sociedade pelos dispositivos tecnológicos, num bios midiático, uma nova forma de organização social da vida, uma nova ordem comunicacional (Sodré, 2002, Carvalho \& Lage, 2012, Hepp, 2013, Hjavard, 2012). O poder simbólico da mídia concebe então uma nova ambiência, mas não da mesma ordem da realidade das coisas. Nas questões científicas, especialmente as controversas, a mídia passa então a não só transmitir informações, mas também permitir aos cidadãos ter acesso a possibilidade de avaliar informações públicas sobre Ciência e Tecnologia, podendo ampliar e facilitar o debate entre eles.

Nas questões científicas, especialmente as controversas, a mídia passa então a não só transmitir informações, mas também permitir aos cidadãos ter acesso a possibilidade de avaliar informações públicas sobre Ciência e Tecnologia, podendo ampliar e facilitar o debate entre eles (Braga, 2006).

\section{Objetivos e metodologia}

Este artigo visa analisar como as duas maiores redes de televisão brasileiras apresentaram uma nova descoberta científica aos seus telespectadores em suas revistas eletrônicas televisivas exibidas no domingo à noite: Fantástico e Domingo Espetacular, respectivamente das Redes Globo e Record.

A metodologia utilizada é a análise hermenêutica, uma vez que:

"(...) procura mostrar o papel da interpretação como um processo, uma metodologia, que busca descobrir o originalmente escondido por uma tradição que nos foi legada por uma exegese distorcida, usando para tal de uma destruição, ou seja, de uma desconstrução 
hermenêutica. A desconstrução hermenêutica, assim, não critica o passado, mas o presente e sua abordagem distorcida, subvertendo as explicações tradicionais e seus conceitos dogmaticamente inquestionados, não destruindo de fato, mas procurando revelar possibilidades ainda não percebidas" (Bastos \& Porto, 2017: 316).

Heidegger (cit. in Seibt, 2016) acredita, por meio da hermenêutica, superar o dualismo metafísico que faz uma cisão entre mundo sensível e inteligível através do modelo de relação sujeito-objeto.

Essa metodologia opera sob dois tipos de ângulos: pertencimento, belongness, e distanciamento, distanciation, que podem ser transformados pragmaticamente em outra dupla operação - desconstruction e recovering of meaning, que pode ser compreendida por desconstrução, desmistificação, desmitologização e restauração de sentido (Bastos \& Porto, 2017).

Dessa forma, o pesquisador que utiliza essa metodologia faz uma ida e vinda ao texto, com o intuito de verificar os sentidos que estão "escondidos", fazendo, portanto, um exercício de compreender e interpretar o conteúdo para revelar os significados que estão ocultos. A tarefa interpretativa, no entanto, é aberta e pode proporcionar significados divergentes daqueles propostos pelos sujeitos analisados, sendo, portanto, uma projeção de significados possíveis.

Em suma, a hermenêutica possibilita, meio da interrogação e da reinterpretação, reelaborar historicamente os sentidos e os significados da compreensão humana, estabelecendo, portanto, uma construção de uma ação comunicativa na abrangência da dimensão comunicacional (Bastos \& Porto, 2017). Os dados das duas análises dos programas televisivos foram, posteriormente, comparados para verificar diferenças ou semelhanças entre as coberturas jornalísticas.

\section{Análise das reportagens exibidas pelo Programa Fantástico da TV Globo}

O Fantástico é um programa dominical produzido em formato de revista eletrônica televisiva desde 1973 pela Rede Globo. Apresentados por Poliana Abritta e Tadeu Schmidt nas noites de domingo, seu conteúdo reúne jornalismo e entretenimento com o intuito de oferecer ao público os principais assuntos discutidos durante a semana no Brasil e no mundo.

A primeira notícia foi veiculada no dia 18 de outubro de 2015. No site do programa, a descrição do vídeo que traz a matéria é a seguinte: "Uma suposta pílula mágica que promete curar todos os tipos de câncer atraiu centenas de pessoas para o interior de São Paulo. Mas não se engane! A chamada 'fosfoetanolamina' não é remédio e nunca foi testada em seres humanos. O doutor Drauzio Varella explica e alerta". Somente pela resenha, é possível depreender o posicionamento da revista eletrônica televisiva semanal, que já fomenta dúvidas e gera incerteza de que realmente a substância tenha o poder de curar neoplasias malignas.

A reportagem tem a duração de 7 minutos e 39 segundos, sendo a mais longa das quatro notícias do programa que serão analisadas neste artigo. Logo de início, os dois apresentadores mostram os seus pareceres contrários ao composto químico, utilizando as frases: "Não dá para confiar nesse suposto remédio" e "Drauzio explica e faz um alerta importante". 
Nessa primeira reportagem, ele aparece como repórter, fazendo perguntas às fontes e também tecendo conexões entre as falas dos personagens. O Fantástico legitima o lugar de fala de Varella, dando para ele o "poder" de especialista no assunto e transferindo o conhecimento desse papel ao público.

Em nenhum momento, o programa televisivo, no entanto, chama a substância de fosfoetanolamina sintética. O termo "pílula do câncer", nesse contexto, também ganha conotação negativa diante da falta de evidências científicas e, ao mesmo tempo, pode reforçar o interesse e a confiança dos telespectadores em relação à droga.

Varella não preza pela imparcialidade do jornalismo ao utilizar durante o conteúdo as frases: "Esses comprimidos que vêm num saquinho plástico, sem rótulo e nem bula, têm enganado muita gente"; "Pílula mágica"; "Decidiu há 20 anos, por conta própria, entregar gratuitamente comprimidos de fosfoetanolamina direto para pacientes com câncer. Sem testes, sem controle, sem sequer saber a dose ideal e sem informar à USP"; "Esse processo é absurdo"; "Universidade não é fábrica de remédios"; "USP passou a ser obrigada a produzir um remédio ilegal"; "Nunca existirá uma única droga capaz de tratar todos os tipos de câncer"; "Despertar esperanças vãs, descabidas, acrescenta mais desespero" e "Não caia em aventuras perigosas e, mais importante, não interrompa o tratamento sem orientação médica".

Outro detalhe que chama atenção é a desproporcionalidade de fontes à favor e fontes contrárias à "pílula do câncer": há quatro especialistas que não são favoráveis à fosfoetanolamina sintética contra apenas um que defende o possível fármaco, sendo que este é o professor aposentado Gilberto Chierice, um dos responsáveis pela criação da droga. Ele, no entanto, não quis gravar entrevista para o Fantástico e, por isso, o programa recorreu à uma matéria gravada por outro programa da própria emissora, o Bom Dia Brasil.

Varella utiliza os comentários e suposições do diretor-presidente da Agência Nacional de Vigilância Sanitária (Anvisa), Jarbas Barbosa, do médico oncologista Antonio Carlos Buzaid - chamado na matéria de "um dos mais respeitáveis do país" e que teria procurado o professor Chierice em 2008 para um possível teste clínico - e do presidente eleito da Sociedade Brasileira de Oncologia Clínica, Gustavo Fernandes, além de nota da Universidade de São Paulo (USP) sobre o caso, para dar coerência ao seu pensamento e apresentá-lo ao público.

O encerramento da reportagem traz um apelo, de fundo emocional, do próprio Varella. Ele conta a história de seu próprio irmão, que morreu aos 45 anos em decorrência de um câncer de pulmão. O médico, por isso, compreende o drama familiar vivido por inúmeras pessoas em todo o Brasil. O especialista também solicita ao fim do conteúdo televisivo que os pacientes com câncer avaliem o uso da fosfoetanolamina (não se usa o termo sintética), procurem os seus médicos e sigam as recomendações fornecidas por eles.

O Fantástico faz outra reportagem sobre a fosfoetanolamina sintética em 10 de abril de 2016. Com duração de cinco minutos e cinquenta segundos, a cobertura aborda sobre a lei de liberação do composto químico que foi aprovada no Senado Federal e na Câmara dos Deputados e que estava para ser sancionada pela ex-presidente Dilma Rousseff. 
A matéria inicia com a frase "Você viu o alerta aqui no Fantástico" dita pela reportagem Cristina Serra que, em seguida, faz uma retrospectiva breve do assunto, com trechos do conteúdo veiculado em 2015 pelo próprio programa. Frases como "Ninguém sabe se esse composto funciona ou não em seres humanos" e "É um risco" apontam para a opinião expressa pelo veículo de comunicação, que não "acredita" que a droga poderá ter algum efeito no combate ao câncer.

Não há nenhuma fonte à favor do composto químico em todos os quase seis minutos de conteúdo jornalístico, o que aponta para uma parcialidade da emissora, que busca maneiras de "convencer" o público sobre os possíveis riscos de se consumir uma substância sem os comprovados testes clínicos.

Um pouco mais de um mês desde a veiculação da segunda matéria, o Fantástico traz a terceira reportagem sobre o assunto. Em 22 de maio de 2016, o programa dominical informa que o Supremo Tribunal Federal (STF) suspendeu a lei que liberava a "pílula do câncer", que tinha sido sancionada pela ex-presidente Dilma Rousseff sob forte pressão popular.

Com quatro minutos e seis segundos, a repórter Giuliana Girardi mostra pela, pela primeira e única vez em todas as quatro reportagens analisadas neste artigo, uma paciente portadora de câncer. Regiane Costa Hespanhol, com então 38 anos, considera o composto químico como "falso milagre" e Giuliana acrescenta o comentário "ao contrário dela, teve gente que confiou" para o público. Esse fato confirma toda a trajetória do Fantástico em desmistificar o suposto fármaco e em fomentar o debate público com opiniões contrárias à "pílula do câncer".

Entre as fontes entrevistadas, há o médico oncologista do Hospital Israelita Albert Einstein Rafael Kaliks, que mostra dois exames de um antigo paciente. O primeiro aponta o corpo dele sem tomar a fosfoetanolamina sintética, com o câncer controlado na região do abdômen; já a segunda mostra o mesmo indivíduo dois meses depois de tomar as cápsulas e com vários tumores pelo corpo, indicando que o câncer se tornara metastático. Não há, no entanto, nenhum outro personagem que fale os benefícios que o composto químico possa ter feito no tratamento contra as neoplasias.

O diretor-presidente da Anvisa, Jarbas Barbosa, é entrevistado novamente e há a aparição do presidente do Conselho Federal de Medicina, Carlos Vital, que considera que a fosfoetanolamina é uma "substância sem comprovação científica".

A última matéria da série de reportagens transmitidas pelo Fantástico sobre o assunto foi lançada no dia 19 de fevereiro de 2017 e tem duração de 6 minutos e 25 segundos. No início da reportagem, a repórter Giuliana Girardi mostra o suplemento alimentar de fosfoetanolamina sintética que foi registrado em empresa nos Estados Unidos e que seria em breve vendido pela internet. O biólogo Marcos Vinícius de Almeida e o médico oncologista Renato Meneguelo são apresentados ao público e é informado que eles foram parceiros de Chierice por 15 anos no desenvolvimento da fosfoetanolamina sintética.

Giuliana Girardi garante, por meio da fala de Almeida e Meneguelo, que a fórmula presente no suplemento alimentar é a mesma da "pílula do câncer" distribuída por 20 anos pelo professor Chierice. Esse fato, portanto, traz uma possibilidade para os pacientes com câncer, que poderão, por exemplo, importar as cápsulas dos Estados Unidos e consumi-las no Brasil. Nesse momento, esses indivíduos só tinham acesso ao composto por meio de 
decisão judicial, processo moroso e custoso, que nem sempre dava resultados favoráveis aos portadores da doença.

Drauzio Varella volta a explanar sua opinião sobre a fosfoetanolamina sintética. Para ele, os pesquisadores são "espertalhões" e há, mais uma vez, um apelo para que o público "não caia nessa". Ele comenta que "isso é charlatanismo para explorar pessoas doentes".

\section{Análise das reportagens exibidas pelo Programa Domingo Espetacular da TV Record}

O programa Domingo Espetacular é exibido semanalmente desde abril de 2004 pela emissora com o segundo lugar em audiência nacional: a TV Record. Também se autointitula como uma revista eletrônica televisiva de entretenimento e informação, apresentado pelos jornalistas Paulo Henrique Amorim e Fabiana Scaranzi.

A primeira reportagem do programa Domingo Espetacular sobre a fosfoetanolamina sintética foi exibida em 18 de outubro de 2015, no mesmo dia do Fantástico, com 13 minutos e 18 segundos. Veio sob a retranca de "Reportagem da Semana" sob o título "Fosfoetanolamina: a verdade sobre a suposta cura do câncer". A chamada da reportagem pelos apresentadores do programa aponta que um remédio em fase experimental está no centro de uma discussão inédita no Brasil. "A Justiça obrigou uma Universidade a distribuir a substância que seria capaz de curar o câncer. Médicos e cientistas se dividem: será correto receitar um remédio que ainda não está pronto? Mesmo que ele seja a única esperança para os doentes?".

A reportagem abre com a paciente Alcilena Cincinatus, de 68 anos, com um câncer agressivo em estágio avançado no pâncreas e no fígado. Ela chegou a tomar cerca de 30 remédios por dia durante um ano, incluindo quatro diferentes tipos de quimioterápicos, mas nenhum tinha conseguido conter o avanço da doença. Os médicos informaram que não havia mais nada a fazer para deter a enfermidade. Então os filhos começaram a pesquisar outros tratamentos alternativos para a mãe em estágio terminal. Realizaram diversas buscas pela internet e por indicação de um tio que mora nos Estados Unidos, chegaram à fosfoetanolamina sintética, desenvolvida pela USP.

Ao contrário da abordagem do programa Fantástico, aqui a substância é tratada como "fosfoetanolamina sintética", indicando que foi desenvolvida em um laboratório do Instituto de Química da Universidade de São Paulo há mais de 20 anos. O programa também apresenta em animação o suposto mecanismo de atuação do composto no corpo humano - ainda não confirmado em testes clínicos.

O professor Gilberto Chierice, desenvolvedor da substância, também ganha outro status, concedendo entrevista à produção do programa Domingo Espetacular. Ele informou que a fosfoetanolamina existe em todo corpo humano; e que já foi estudada anteriormente, portanto não é inédita. A novidade é a síntese química desenvolvida por ele, que gera uma substância de "altíssimo grau de pureza e rendimento de reação". Com essa abordagem, reforça-se o lugar de cientista para o criador da substância, ao invés daquele de "espertalhão" e "charlatão, retratado pelo Fantástico. Chierice reitera em sua entrevista que não fez testes clínicos - por não ser médico, e sim químico -; mas que os pacientes traziam o retorno. "Mesmo sem ter a prática médica, os pacientes me diziam: 'Aqui estão os meus exames, que estão dizendo que não tenho mais nada'. Isso eu ouvi centenas de vezes". Segundo o professor, os pacientes eram enviados pelos médicos oncologistas do Hospital Amaral Carvalho (HAC) ao seu laboratório na USP para pegar a substância gratuitamente. "Era um convênio que nós tínhamos". O HAC é uma unidade hospitalar 
especializada no tratamento de pacientes portadores de câncer e está localizada em Jaú (SP), cerca de 97 quilômetros de São Carlos (SP).

A reportagem começa a contar a batalha judicial travada pelos pacientes com câncer para ter acesso à pílula após a publicação da portaria IOSC 1.389/2014 pela USP, retornando a história da paciente Alcilena Cincinattus, do início da reportagem. O seu caso foi parar no Supremo Tribunal Federal (STF) que acatou o pedido da família, em defesa do seu direito à saúde previstos na Constituição Federal.

Antes de tomar a pílula, a paciente estava debilitada, sem conseguir se locomover e tomando morfina quatro vezes ao dia para amenizar as dores. Poucos dias após começar a tomar a droga, a equipe do programa Domingo Espetacular encontrou a dona de casa mais animada e bem-disposta, surpreendendo a equipe ao descer das escadas de sua casa sozinha. Mesmo com uma sonda para a alimentação, a paciente afirmou que estava bem melhor após a ingestão da cápsula, três vezes ao dia. "A recuperação dela ainda precisa ser confirmada por estudos clínicos", pondera a repórter. O Domingo Espetacular também faz referência aos inúmeros casos divulgados na internet de pessoas que se dizem curadas após o uso da substância, exibindo trechos de alguns vídeos.

O contraponto é dado pelo diretor da Sociedade Brasileira de Oncologia, Volney Lima, que orienta que: "Atualmente nenhum paciente deve receber essa medicação, não foi aprovada para uso em pacientes com câncer, não foi testada clinicamente. Então médico nenhum está autorizado a prescrever esse tipo de medicação".

A reportagem ainda traz a fala do defensor público Daniel de Macedo, informando que irá ajuizar uma ação civil pública para que os pacientes possam ter acesso à substância. $\mathrm{E} o$ professor Chierice afirma que se liberada e aprovada pela Anvisa, poderá ser distribuída de graça para os doentes. "Alguém fez os cálculos, e o custo de produção é de 10 centavos. A patente será doada no mesmo instante que eu tiver garantia de que o medicamento será fornecido gratuitamente pelo Governo".

A abordagem desse primeiro programa reforça o aspecto simbólico do composto químico, e tenta inferir o motivo de tanta controvérsia na esfera pública: "Uma cápsula capaz de curar o câncer. Essa é uma ideia poderosa, por isso tanta polêmica", destaca a repórter. Nota-se que o termo "cápsula" é preferido em vários momentos dessa cobertura jornalística, ao invés de "pílula", "droga" ou "medicamento". A opção por um termo mais neutro e imparcial para retratar a substância revela o cuidado da produção do programa Domingo Espetacular - não só nesse caso, mas em toda a reportagem - em não trazer estereótipos já consolidados e ouvir fontes diversas (favoráveis e desfavoráveis), fatos que contribuem para que a interpretação do caso seja realizado pelo telespectador, sem tentar induzir e/ou manipular um determinado sentido.

A segunda reportagem exibida pelo programa foi ao ar, uma semana depois, em 25 de outubro de 2016, sob o título "Novas revelações sobre a fosfoetanolamina", e contém 17 minutos e 23 segundos de duração. Na chamada, os apresentadores Paulo Henrique Amorim e Fabiana Scaranzi afirmam: "Os bastidores da polêmica que sacode o Brasil há duas semanas. A cápsula desenvolvida por brasileiros que seria capaz de curar o câncer. Afinal, por que as pesquisas sobre algo tão importante estão paradas há mais de vinte anos? O Domingo Espetacular traz revelações que explicam porque essa cápsula do câncer pode se tornar um verdadeiro escândalo." 
A abertura da reportagem apresenta novamente o ponto de vista dos pacientes, que peregrinam diariamente ao laboratório de química da USP, em São Carlos. E mostra o caso do menino André, com câncer no cérebro, sem alternativa de tratamento pela medicina não é citado o seu sobrenome. A família afirma que ele está muito mais ativo e apresentou melhora significativa em seu quadro clínico, depois que começou a tomar as cápsulas. Ele recuperou o movimento do lado esquerdo do corpo, e apresenta os laudos médicos: "No mês de agosto, o tumor tinha 3,8 centímetros $(\mathrm{cm})$, mas depois de 20 dias tomando a substância, o tumor diminuiu de forma impressionante, chegando a $1,7 \mathrm{~cm}$, menos $\mathrm{da}$ metade do tamanho original". O pai comemora a redução do tumor, informando que já estaria morto, por não estar mais vascularizado. Novamente, a reportagem destaca que assim como André - há vários casos de diversos pacientes na internet que relatam melhoras em seu estado de saúde após o uso da substância e o seu suposto mecanismo de atuação no corpo humano. Por outro lado, revela que as autoridades e a comunidade científica se dizem preocupados com a falta de comprovação de sua eficácia e segurança.

A equipe de produção do Domingo Espetacular traz também outros trechos da entrevista com o professor Gilberto Chierice, chamado agora de "pai da fosfoetanolamina". Ele revelou que esteve fabricando cerca de 50 mil cápsulas por mês nos últimos anos, atendendo cerca de mil pacientes mensalmente. Como ainda não foi regulamentada como medicamento, a USP proibiu a distribuição após a aposentadoria do professor em 2014. Por essa razão, pacientes do Brasil e do exterior começaram a entrar na Justiça. A esposa de um paciente oncológico, Manuela Pinaffi, lamenta a dificuldade em ter acesso a substância: "Minha única esperança é a fosfo". Já o médico oncologista, Antônio Buzaid, critica o posicionamento da Justiça brasileira. "Quem é o responsável se alguém tiver algum problema grave com a droga? O juiz? O Supremo (Tribunal Federal)? Quem? Então não é assim que se faz".

O Hospital Amaral Carvalho, negou em nota, apresentada pela reportagem, a existência de testes com seres humanos com a fosfoetanolamina sintética. O Hospital indica apenas que em 1996 foi firmado um convênio com a USP de cooperação científica para estudos de substâncias, que não tem relação com a fosfoetanolamina. Contudo, documentos exclusivos acessados pela equipe do programa revelam que o Ministério da Saúde aprovou testes de novas drogas para o tratamento de câncer no Hospital Amaral Carvalho em 1995, meses antes do convênio assinado pela USP. Um documento adicional da Unesp - um laudo de toxicidade - apresenta a fosfoetanolamina sintética como um produto do Hospital Amaral Carvalho. Por telefone, o diretor do Hospital Amaral Carvalho, Antônio Cesarino Navarro, confirmou que foi firmado o convênio, mas que não foi executado. Segundo ele, não há nenhum registro de pesquisas clínicas realizadas com seres humanos. Da mesma forma a Anvisa informa que não recebeu nenhum pedido para registro da substância, mas, novamente, documentos exclusivos da produção do Domingo Espetacular revelaram uma reunião com o então diretor Dirceu Brás Aparecido Barbano com o Professor Gilberto Chierice em 26 de janeiro de 2010 para tratar de "Pesquisa Clínica e Tratamento para o Câncer com a Fosfoetanolamina" na Sede da Anvisa em Brasília, DF. Segundo documentos apresentados, uma outra reunião sobre o assunto ocorreu na Fundação Oswaldo Cruz (Fiocruz), instituição de pesquisa ligada ao Ministério da Saúde, em 23 de novembro de 2013, novamente com a presença do mesmo diretor da Anvisa e outros integrantes do Governo. Dois meses depois, a Fiocruz enviou um e-mail ao professor Gilberto informando ter interesse na produção pública da fosfoetanolamina, já que "os resultados apresentados até o momento indicam que o produto poderá vir a ser um importante medicamento 
utilizado no tratamento do câncer". Isso iria requerer, entretanto, a cessão dos direitos patentários, o que foi negado pelos pesquisadores.

Esses documentos podem ser acessados pela internet, mas ainda não haviam sido divulgados em programas de TV. Constituem provas contundentes capazes de promover um clima de desconfiança da opinião pública em relação às autoridades. Com isso, ganha força a ideia de que há uma grande rede conspiratória, envolvendo médicos, hospitais oncológicos e laboratórios farmacêuticos, que atrapalham os estudos clínicos, fundamentais para a regulação da substância pelos órgãos competentes. O câncer é uma das doenças mais rentáveis para área médica, envolvendo cirurgias, quimioterapia e radioterapia. Um tratamento contra o câncer com quimioterapia, por exemplo, custa em média 10 mil reais por sessão, podendo custar milhões de reais para cada paciente.

Dessa forma, a cura do câncer pode ter sido encontrada por pesquisadores brasileiros e sendo impedida de chegar aos milhares de pacientes oncológicos, que todos os anos morrem com a doença. Isso é reforçado pela reportagem com o anúncio da abertura de uma Comissão Parlamentar de Inquérito (CPI) na Assembleia Legislativa de São Paulo para investigar o caso, já que, segundo o Deputado Rafael Silva: "Todas as autoridades têm conhecido do poder de atuação deste composto. E se não atuaram de forma a aprovar isso tudo, é porque tem se curvado aos interesses, talvez escusos, de alguns empresários".

A reportagem segue retratando os resultados obtidos pelos pacientes com o uso da cápsula. A fisioterapeuta Thalita Petri, com câncer no seio, tomou a fosfo durante dois anos, obtendo melhoras significativas em seu quadro clínico. "Cada vez que eu voltava no meu médico, ele se espantava. Ele falava: "Nossa, Thalita, você está ótima. E eu respondia: "Estou, estou ótima" E ele: "Ainda tomando aquele medicamento? E eu: "Ainda". Ela se casou, teve uma filha e após seis anos, diz-se curada do câncer. O contraponto é dado pelo mesmo médico oncologista ouvido anteriormente pela reportagem, Antônio Buzaid. "Em casos como de Thalita, é bem provável que apenas a cirurgia já tenha sido suficiente para curar a doença. Isso acontece em $80 \%$ dos casos".

Por fim, a reportagem mostra receitas de médicos oncologistas, prescrevendo a fosfoetalonamina sintética. O destaque vai para uma receita de um médico do renomado hospital Sírio Libanês, de São Paulo, encaminhando pacientes para o professor Gilberto Chierice na USP. E o drama da senhora Gladis, de 78 anos, que viajou sozinha três dias de ônibus de Porto Velho, Rondônia, até a USP de São Carlos na esperança de voltar para a casa como que considera "a última chance do filho". Seu choro compulsivo ao saber que a USP não estava mais distribuindo a substância fecha a reportagem.

\section{Análise comparativa das narrativas sobre a fosfoetanolamina sintética}

A análise das quatro reportagens transmitidas pelo Fantástico aponta para uma parcialidade do programa de televisão em assunto de cunho científico. Há diversos elementos que comprovam, por meio da fala das fontes, dos repórteres e dos apresentadores, que é contrário a liberação do composto químico. Assim, o conteúdo televisivo "fere" o princípio de objetividade e imparcialidade do jornalismo e busca se posicionar desde o primeiro instante contra a fosfoetanolamina sintética. O Fantástico, com exceção da última reportagem, não entrevista nenhum dos pesquisadores e não há pacientes que tomaram a pílula e indicaram seus benefícios. 
A revista eletrônica televisiva semanal se posiciona de um lado do debate sobre a "pílula do câncer" e se mantém na mesma posição até o fim, com o uso de expressões pejorativas como "charlatanismo" e "espertalhões". O público que não acompanha outros conteúdos e formatos jornalísticos pode ser levado a crer que a fosfoetanolamina sintética foi constituída para "enganar" os pacientes com câncer.

Por outro lado, as reportagens do Domingo Espetacular têm uma duração maior, e trazem mais contrapontos a questões, com inúmeras fontes favoráveis, incluindo um dos criadores da substância, o professor e pesquisador Gilberto Chierice. Também chama a atenção que as narrativas dos pacientes que fizeram uso da substância são valorizadas, e não desqualificados como no Fantástico. Os dramas dos pacientes e seus familiares são tratados como pano de fundo e aspecto central de toda a polêmica, ao contrário do Fantástico que destaca a falta de evidências científicas e de registro pela Agência Nacional de Vigilância Sanitária (Anvisa).

Abaixo um quadro síntese da cobertura dos programas Fantástico e Domingo Espetacular sobre a fosfoetanolamina sintética:

\begin{tabular}{|c|c|c|}
\hline $\begin{array}{l}\text { Características } \\
\text { Programa }\end{array}$ & Fantástico & Domingo Espetacular \\
\hline Termo utilizado & \begin{tabular}{|ll} 
Pílula & mágica, \\
Fosfoetanolamina
\end{tabular} & $\begin{array}{l}\text { Cápsula, Fosfoetalonamina } \\
\text { sintética. }\end{array}$ \\
\hline Enfoque central & $\begin{array}{l}\text { Falta de evidências científicas } \\
\text { e de registro pela Anvisa. }\end{array}$ & $\begin{array}{l}\text { Dramas dos pacientes e seus } \\
\text { familiares }\end{array}$ \\
\hline Principais fontes & Médico Drauzio Varella & $\begin{array}{l}\text { Professor Gilberto Chierice e } \\
\text { pacientes }\end{array}$ \\
\hline Fontes similares & $\begin{array}{l}\text { Diretor-presidente da Anvisa, } \\
\text { Jarbas Barbosa, médico } \\
\text { oncologista Antônio Buzaid, } \\
\text { professor Gilberto Chierice, } \\
\text { presidente eleito da } \\
\text { Sociedade Brasileira de } \\
\text { Oncologia Clínica e o médico } \\
\text { Renato Meneguelo. }\end{array}$ & $\begin{array}{l}\text { Diretor-presidente da } \\
\text { Anvisa, Jarbas Barbosa, } \\
\text { médico oncologista Antônio } \\
\text { Buzaid, professor Gilberto } \\
\text { Chierice, presidente eleito } \\
\text { da Sociedade Brasileira de } \\
\text { Oncologia Clínica e médico } \\
\text { Renato Meneguelo. }\end{array}$ \\
\hline $\begin{array}{l}\text { Informações } \\
\text { exclusivas }\end{array}$ & Não há & $\begin{array}{l}\text { Convênio com Hospital } \\
\text { Amaral Carvalho, Registro } \\
\text { de reuniões com Anvisa e } \\
\text { Fiocruz }\end{array}$ \\
\hline $\begin{array}{l}\text { Tempo de duração das } \\
\text { reportagens }\end{array}$ & 7'39"; 5'50"; 4'6"; 6'25" & $13^{\prime} 18^{\prime \prime}$ e $17^{\prime} 22^{\prime \prime}$ \\
\hline Data da exibição & $\begin{array}{l}\text { 18/10/15; 10/04/16; 22/05/16; } \\
19 / 02 / 17\end{array}$ & $18 / 10 / 15$ e $25 / 10 / 2015$ \\
\hline
\end{tabular}


Tabela 1 - Quadro comparativo da cobertura dos programas Fantástico e Domingo Espetacular sobre a fosfoetanolamina sintética. Fonte: Elaborado pelas autoras.

\section{Considerações finais}

As notícias publicadas sobre a fosfoetanolamina sintética fomentaram discussões que extrapolaram o meio científico, promovendo debates sobre temas como o direito legal à esperança de cura para pacientes em estado terminal, os interesses das indústrias farmacêuticas, os limites éticos de atuação de pesquisadores, a judicialização da medicina e os modos como a mídia consegue ou não influenciar e interferir nas mais diversas esferas da vida social.

Diante de sua capacidade de alcançar uma grande audiência, a televisão deve ser considerada um meio de comunicação privilegiado para divulgação de assuntos científicos. No caso analisado, os programas televisivos, de fato, podem ter prestado um importante serviço público ao tornar visível a possibilidade do acesso praticamente gratuito à cura do câncer, além de promover uma invenção desenvolvida por cientistas brasileiros. Entretanto, como o acesso foi dificultado pelas autoridades governamentais, científicas e regulatórias, sua cobertura gerou um amplo questionamento ético, moral e até científico por parte dos públicos.

Diante de sua capacidade de alcançar uma grande audiência, a televisão deve ser considerada um meio de comunicação privilegiado para divulgação de assuntos científicos. No caso analisado, os programas televisivos, de fato, podem ter prestado um importante serviço público ao tornar visível a possibilidade do acesso praticamente gratuito à cura do câncer, além de promover uma invenção desenvolvida por cientistas brasileiros. Entretanto, como o acesso foi dificultado pelas autoridades governamentais, científicas e regulatórias, sua cobertura gerou um amplo questionamento ético, moral e até científico por parte dos públicos.

Essa disputa simbólica e discursiva presente na opinião pública brasileira em relação à fosfoetanolamina sintética ficou evidente na polifonia demonstrada por esses dois veículos de comunicação. Duas versões da mesma história foram apresentadas para o público, praticamente no mesmo horário, em duas emissoras diferentes. Enquanto o Fantástico focava nos perigos de se utilizar um composto químico sem comprovação terapêutica, o Domingo Espetacular direcionava o seu enfoque para os relatos dos pacientes e para as possíveis melhorias atribuídas à "pílula do câncer".

Por outro lado, é importante considerar que diante dos emissores de mensagens e produtores institucionalizados de sentidos - os veículos de comunicação -, os públicos não permanecem passivos, mas se mantêm e articulam as mensagens recebidas pela mídia em estruturas abertas, múltiplas e indeterminadas. Os indivíduos passam a construir a sua própria versão dos fatos diantes das narrativas apresentadas, caso eles tenham tido a oportunidade de assistir aos dois programas televisivos - seja na mesma hora, com a alternância de canais, ou por outros meios, como a internet, onde os conteúdos são disponibilizados posteriormente; seja no próprio site da emissora ou na rede social YouTube.

Esse fato é revelado, por exemplo, ao observar que as mensagens da mídia hegemônica especialmente da Rede Globo -, mesmo com o amplo alcance na sociedade brasileira não 
detém mais tanto poder em direcionar irrestritamente a opinião pública e de influenciar a realidade. Mesmo com a sua cobertura fortemente negativa sobre a questão, alguns meses após a exibição do primeiro programa, foi aprovada a Lei Federal 13.269/16, que autorizou o uso da substância fosfoetanolamina sintética por pacientes diagnosticados com neoplasia maligna, sem testes clínicos formais e de registro da substância como medicamento no órgão da vigilância sanitária.

Se acaso, os públicos tiveram pouco espaço na televisão para expor seus dramas (aqui apenas identificada em dois programas da Rede Record) e buscar informações, as redes sociais constituíram (e ainda constituem) espaço privilegiado para compartilhamento de dramas e experiências pessoais em busca da cura do câncer; como indicadas por sondagens livres não exploradas neste artigo. Isso pode ter sensibilizado e mobilizado agentes políticos ao aprovar uma lei que liberou o acesso à fosfoetanolamina sintética - mesmo que suspensa dois meses depois em liminar ajuizada pela Associação Médica Brasileira no Supremo Tribunal Federal.

Esse caso nos faz pensar, portanto, a midiatização como uma força de produção e reprodução de sentidos permeável a uma construção individual. O sistema de resposta social de José Luiz Braga (2006) corresponde à esse procedimento, uma vez que o pesquisador reconhece que a sociedade atribui um sentido social às ações e produtos oriundos dos meios de comunicação. Desde as primeiras interações midiatizadas, e não apenas com a chegada da internet, a sociedade age e produz não só com os veículos de comunicação ao desenvolvê-los e atribuir-lhes objetivos e processos, mas sobre os seus produtos, direcionando e atribuindo, dessa forma, um sentido social. Embora esse sistema, de acordo com Braga (2006), ainda esteja em seu estágio embrionário, é possível depreender que a identificação e análise dos dispositivos de resposta social criados pelos produtos comunicacionais em circulação pode remeter às formas de como a sociedade enfrenta sua mídia, uma alusão ao título do livro lançado pelo pesquisador brasileiro.

Em suma, este artigo levantou pistas que indicam desgaste e disruptura nas formas de comunicação de ciência na mídia, principalmente na televisão, que merecem investigação mais aprofundada. A análise aqui proposta possui caráter exploratório e não pretende ser conclusiva. Recomendamos, portanto, outras análises de produtos jornalísticos, redes sociais digitais e outros dispositivos midiáticos para que possamos ampliar o entendimento sobre a comunicação de ciência na atualidade. 


\section{Referencias bibliográficas}

ANCINE. TV Aberta no Brasil: aspectos económicos e estruturais. 2015. Recuperado de: https://oca.ancine.gov.br/sites/default/files/repositorio/pdf/Estudo_TVAberta_2015.pdf. [Acessado em: 5 de outubro 2018].

BASTOS, Fernando \& PORTO, Sérgio Dayrell (2017): "Análise hermenêutica", en Duarte, Jorge \& Barros, Antonio: Métodos e técnicas de pesquisa em comunicação, São Paulo, Atlas, pp. 316-329.

BRAGA, José Luiz (2006): A Sociedade enfrenta a sua mídia: dispositivos sociais de crítica midiática. São Paulo, Paulus.

BUCCHI, Massimiano (2008). "Of deficits, deviations and dialogues: theories of public communication of science", en Bucchi, Massimiano \& Trench, Brian: Handbook of public communication of science and technology, London, Routledge.

BUENO, W. C. (2010). Comunicação cientifica e divulgação científica: aproximações e rupturas conceituais. Informação \& Informação, Londrina, v. 15, p. 1-12. Número especial.

DI GIULIO, G. M.; Figueiredo, B. R. (2006): "Divulgação científica nas áreas ambientais e saúde pública", en Sousa, C. M.; Ferreira, J. R. \& Bortoliero, S. Jornalismo científico e educação para as ciencias, Taubaté, Cabral Editora e Livraria Universitária.

EPSTEIN, Isaac. (2012) Comunicação da ciência: rumo a uma teoria da divulgação científica. Revista Organicom, ano 9, edição especial, números 16/17.

ESTEVES, João Pissarras Nunes. Sociologia da Comunicação. Lisboa: Fundação Calouste Gulbenkian, 2011

GOMES, D. C. A. (2015) Hermenêutica e comunicação: contribuições para compreender a teoria da interpretação e sua aplicação na sociedade midiática. NAMID/UFPB, ano 9, n. ${ }^{\circ} 4$.

HABERMAS, J. (2012): A transformação estrutural da esfera pública: investigações sobre uma categoria da sociedade burguesa. Tradução João José Pissarra Nunes Esteves. Lisboa, Fundação Calouste Gulbenkian.

HALL, S. (1980): "Encoding/decoding", en Centre for Contemporary Cultural Studies (Ed.): Culture, Media, Language: Working Papers in Cultural Studies. London: Hutchinson, pp. 128-38.

HEPP, A. (2013). Cultures of mediatization. Cambridge, Polity Press.

HJARVARD, S. (2015). Da mediação à midiatização: a institucionalização das novas mídias. Parágrafo. V. 2, nº 3, pp. 51-62.

HJARVARD, S. (2014). Midiatização: conceituando a mudança social e cultural. MATRIZes. V. 8, nº 1. São Paulo, pp. 21-44. 
HJARVARD, S. (2012). Midiatização: teorizando a mídia como agente de mudança social e cultural. MATRIZes. Ano 5, nº 2. São Paulo, pp. 53-91.

IBGE. Pesquisa Nacional por Amostra de Domicílios Contínua - PNAD Contínua: acesso à internet e à televisão e posse de telefone móvel celular para uso pessoal. 2016. Recuperado de: https://www.ibge.gov.br. [Acessado em: 5 outubro 2018].

LIPPMANN, W. (2008). Opinião pública. Petrópolis, Vozes.

LUHMANN, N. (2000). The reality of the mass media. Stanford, CA, Stanford University Press.

OLIVEIRA, F. (2012). Jornalismo científico. São Paulo, Contexto.

SODRÉ, M. (2002). Antropológica do espelho: uma teoria da comunicação linear e em rede. Petrópolis, Vozes.

SEIBT, C. L. (2016): "A hermenêutica heideggeriana e a questão do conhecimento". Conjectura - Filosofia e Educação, V. 21, nº 3, Caxias do Sul (RS), pp. 188-214.

SCHUDSON, M. (2010) Descobrindo a notícia: uma história social dos jornais nos Estados Unidos. Petrópolis, Vozes.

THOMPSON, J. (2007). Ideologia e cultura moderna: teoria social crítica na era dos meios de comunicação de massa. Petrópolis, Vozes. 